\title{
PENGARUH SENAM LANSIA TERHADAP PERUBAHAN TEKANAN DARAH PADA PENDERITA HIPERTENSI
}

\author{
Farman Dachi*, Reza Syahputri, Sunthree Gugun Marieta, Patimah Sari Siregar \\ Program Studi S1-Keperawatan, Fakultas Keperawatan dan Kebidanan,Universitas Prima Indonesia, \\ Jl. Danau Singkarak, Gg. Madrasah, Sei Agul, Kec. Medan Barat, Kota Medan, Sumatera Utara 20117, \\ Indonesia \\ *farmandachi96@gmail.com (+6285373613587)
}

\begin{abstract}
ABSTRAK
Hipertensi atau tekanan darah terjadi akibat perubahan struktur pada sistem pembuluh darah perifer. Tujuan mengetahui adanya pengaruh senam lansia terhadap pasien penderita hipertensi pada saat melakukan senam dan setelah melakukan senam lansiadi Puskesmas Pembantu Desa Telaga Tujuh Deli Serdang. Metode penelitian ini adalah mengunakan metode Pre-eksperimen desain dengan mengunakan rancangan One Group Pretest-posttest dengan variabel terikat yaitu tekanan darah pada penderita hipertensi dan variabel bebas yaitu senam lansia, melibatkan kelompok subjek dengan diobservasi sebelum dan sesudah dilakukan intervensi. Populasi sebanyak 60 orang sampel 20 responden dengan menggunakan teknik Purposive Sampling dalam mengumpulkan data. Data yang diolah mengunakan uji statistik T-Test. Hasil dari penelitian diketahui bahwa dari 20 responden, mayoritas responden berjenis kelamin perempuan dan laki-laki, Usia mayoritas responden adalah 50-55 tahun sedangkan minoritas yakni usia 5660 tahun. Kesimpulan bahwa senam lansia memberikan perubahan tekanan darah pada penderita hipertensi juga ada pengaruh umur, jenis kelamin, pendidikan, pekerjaan, dan penyakit riwayat hipertensi pada lansia.
\end{abstract}

Kata kunci: lansia; senam; tekanan darah

\section{THE EFFECT OF ELDERLY EXCERCISE ON CHANGES IN BLOOD PRESSURE IN PATIENTS WITH HYPERTENSION}

\begin{abstract}
Hypertension or blood pressure occurs due to structural changes in the peripheral vascular system. The aim is to determine the effect of elderly exercise on patients with hypertension during exercise and after doing lansiadi exercise at Telaga Tujuh Village Sub-Health Center Deli Serdang. This research method is to use the pre-experimental design method using the One Group Pretest-posttest design with the dependent variable, namely blood pressure in hypertensive patients and the independent variable, namely elderly exercise, involving a group of subjects observed before and after intervention. Population of 60 samples of 20 respondents using purposive sampling technique in collecting data. The data were processed using the $T$ Test statistical test. The results of the study revealed that of the 20 respondents, the majority of respondents were female and male. The age of the majority of respondents was 50-55 years while the minority was 56-60 years old. The conclusion is that exercise in the elderly provides changes in blood pressure in patients with hypertension. There is also an effect of age, gender, education, occupation, and history of hypertension in the elderly.
\end{abstract}

Keywords: blood pressure; elderly; gymnastics 


\section{PENDAHULUAN}

Penyakit hipertensi atau tekanan darah tinggi ini merupakan penyakit dimana tekanan darah batas atas (sytole) lebih dari $140 \mathrm{mmHg}$ dan tekanan darah bawah (diastole) lebih dari $90 \mathrm{mmHg}$. Hipertensi terjadi karna adanya perubahan fungsional atau struktural pada sistem pembuluh perifer. Sehingga menimbulkan kerusakan pada ginjal, jantung, dan otak (Triyanto, 2018).

Organisasi kesehatan dunia (WHO) mengatakan penyebab kematian nomor satu di dunia adalah penyakit hipertensi. Dimana data dari JNC VII (Joint National Committee on Prevention, Detection, Evaluation and Treatment of Hight Blood Pressure. Menyatakan hampir 1 milyar total penduduk dunia mengidap hipertensi dan dimana penderita hipertensi ini lebih banyak pada wanita $30 \%$ dibandingkan pria 29\% (Wahyu, 2015). Hipertensi dengan insiden bervariasi mengenai seluruh bangsa di dunia prevalensi meningkat dengan harapan hidup dan tambahnya usia. Di Amerika Serikat mengatakan penyakit tekanan darah dengan penderita hipertensi yaitu sekitar 39\% dan meningkat sekitar $51 \%$ yang berarti bahwa terdapat 58-65 juta penderita hipertensi diantarnya juga terjadi komplikasi akibat dari penyakit yang dialami yaitu penyakit jantung kongestif $22 \%$, penyakit jantung koroner $26 \%$ dan penyakit serbrovaskular 29\% (Triyanto, 2018).

Prevalensi hipertensi di Indonesia yang di laporkan Riset Kesehatan Dasar bahwa penderita hipertensi sekitar 26,5\% menderita hipertensi. Dan 7,2\% mengetahui dirinya penyakit hipertensi sedangkan $9,4 \%$ yang mengosumsi obat antihipertensi (Wahyu, 2015). Menurut Kementerian Kesehatan prevalensi hipertensi di Provinsi Sumatra Utara sekitar $6,7 \%$ dari jumlah penduduk di Sumatra Utara. Dari data Kemeterian Kesehatan jumlah penduduk Sumatra Utara yang menderita hipertensi yaitu 12,42 juta jiwa (Susanti,dkk 2020).

Hipertensi atau tekanan darah terjadi akibat perubahan struktur pada sistem pembuluh darah perifer. Permasalah kesehatan yang cukup dominan di negara maju yaitu penyakit hipertensi atau tekanan darah tinggi. Ancaman hipertensi ini tidak boleh diabaikan. Hal ini dapat mengakibatkan penurunan curah jantung sehingga tekanan darah menjadi tinggi (Wahyu, 2015). Hipertensi dapat dihindari dengan menghindari faktor resiko dan mencegahnya dengan berbagai cara yaitu mengajarkan pola hidup sehat serta melakukan aktifitas fisik dengan rutin, kebutuhan tidur yang cukup, pikiran yang rileks, tidak mengkonsumsi kafein, rokok, alkohol, dan stress, selanjutnya memberitahukan pola makan yang sehat dengan tidak mengkonsumsi makanan yang berlemak tinggi, tinggi kalori, makanan yang berminyak, mengkonsumsi santan yang berlebihan, mengkonsumsi garam yang berlebihan, dan mengkonsumsi kadar gula tinggi (Eviyanti, 2020).

Tekanan darah tinggi atau hipertensi penyakit yang tidak banyak menimbulkan gejala khas hingga tidak terdiagnosis dalam waktu yang lama. Faktor yang mempengaruhi hipertensi yaitu kelamin, keturunan, merokok, obesitas, stress, alkohol, kurang olaraga dan usia (Wahyu, 2015). Hipertensi terlalu lama dapat mengakibatkan dinding arteri bisa merusak banyak organ vital dalam tubuh maka hipertensi ini harus dikendalikan. Pembuluh arteri, jantung, otak, ginjal, dan mata itu tempat utama yang dipengaruhi hipertensi (Ari Wulandari, 2019). 
Penelitian yang dilakukan (Vedyawati, 2018) tentang pengaruh senam anti hipertensi lansia terhadap penurunan tekanan darah dengan mengunakan metode kuantitatif dengan rancangan preexperiment design One Group Pre test-post dengan pengumpulan data mengunakan Sphygmomanometer air raksa. Hasil dari penelitian, tekanan darah sebelum dilakukan intervensi adalah $(87,5 \%)$ dan tekanan darah setelah dilakukan intervensi adalah normal $(87,5 \%)$.

Senam lansia serangkaian gerak nada yang teratur dan terarah serta terencana yang diikuti oleh orang lanjut usia atau lansia dalam bentuk latihan fisik yang berpengaruh terhadap kemampuan fisik lansia. Aktifitas senam lansia ini akan membantu tubuh agar tetap bugar dan tetap segar karena melatih tulang tetap kuat dan membantu menghilangkan radikal bebas yang berkeliaran dalam tubuh. Senam dengan frekuensi tiga kali seminggu terbukti melenturkan pembuluh darah (Depkes RI, 2017). Tujuan dari senam pada lansia ini antara lain untuk dapat meningkatkan daya tahan, kekuatan, koordinasi tubuh, memelihara kesehatan. Selain itu senam lansia juga dapat menunda perubahan fisiologis yang biasanya terjadi pada proses penuaan muskulosketal, penurunan kekuatan dan fleksibilitas, peningkatan kerentanan terhadap cedera, penurunan kelenturan struktur sendi, serta menghindari lansia dari hipertensi(Stanley dan Beare, 2017).

Lansia suatu proses yang di alami dan itu sudah ditentukan oleh Tuhan Yang Maha Esa. Pada akhirnya dimana semua orang akan mengalami proses menjadi tua, pada masa tua adalah dimana masa hidup manusia yang terakhir. Dimasa ini seseorang akan mengalami kemunduran fisik baik secara mental dan sosial secara bertahap (Rahmi,dkk 2016). Untuk selanjutnya usia lansia ini merupakan salah satu dimana di fase ini suatu hidup yang akan di alami oleh setiap manusia, meskipun usia akan terus bertambah dan dengan di iringi berbagai penurunan fungsi organ tubuh akan tetapi dimana pada lansia ini akan tetap dapat menjalani hidup sehat. Salah satu hal yang sangat penting untuk di ingat adalah merubah kebiasaan yang selama ini tidak menjaga kesehatan lebih menjaga kesehatan lagi dan tidak hanya meninggalkan kebiasaan buruk yang dapat mengganggu kesehatan selama ini, tetapi ada beberapa pola hidup sehat yang perlu diketahui seperti olahraga dan menjaga pola makan memang harus dilaksanakan secara rutinitas (Ifansyah,dkk 2015).

Dalam waktu hampir lima tahun, persentase lansia Indonesia sangat meningkat sekitar dua kali lipat (19712020), yaitu menjadi 9,6 persen (25 juta-an) dimana lansia perempuan sekitar satu persen lebih banyak dibandingkan lansia laki-laki (10,10 persen banding 9,10 persen). Dari seluruh lansia yang ada di Indonesia ini, lansia muda (60-69 tahun) jauh dominasi dengan besaran yang mencapai 63,82 persen, selanjutnya diikuti oleh lansia madya (70-79 tahun) dan lansia tua (80+ tahun) dengan besaran masing-masing 27,68 persen dan 8,50 persen (Badan Pusat Statistik, 2019).

Jumlah prevalensi menurut (WHO), jumlah lansia sebanyak $8 \%$ atau sekitar 142 juta jiwa. Pada tahun 2050 diperkirakan banyaknya lansia mencapai 3 kali lipat dari tahun ini. Pada tahun 2000 banyaknya lansia sekitar $5.300 .000(7,4 \%)$ dari seluruh populasi sedangkan pada tahun 2010 banyaknya lansia $24.000 .000(9,77 \%)$ 
dari seluruh populasi dan tahun 2020 diperhintungkan jumlah lansia ini akan meningkat sebanyak 28.800 .000 $(11,34 \%)$ dari total populasi (Eviyanti, 2020).

Hasil penelitian yang dilakukan oleh Fitria Saftarina (2017). Pengaruh Senam Lansia Terhadap Perubahan Tekanan Darah Pada Penderita Hipertensi Di Wilayah Dusun Kwarasan Nogotirto Sleman Yogyakata, pada penelitian ini menunjukkan bahwa pemberian senam lansia dapat menurunkan tekanan darah sistolik dan diastolik.

Hasil survei awal yang dilakukan pada bulan Oktober di Puskesmas Pembantu Desa Telaga Tujuh Kecamatan Deli Serdang Kabupaten Deli Serdang 2021.Jumlah lansia di desa telaga tujuh sebanyak 60 dan 20 orang lansia menderita hipertensi dan mengandalkan obat dari puskesmas. Lansia mengangap bahwa hipertensi penyakit biasa dan tidak menggangu aktivitas sehari-hari. diantara lansia penderita hipertensi mengalamiadanya gejala kesemutan, bengkak pada bagian kaki, tangan, apa lagi pada jari-jari dan sering merasakan pusing disaat tekanan darah tinggi. Lansia mengatasinya adanya gejala dengan melakukan aktivitas fisik seperti jalan kaki dan pergi ke sawah. Namun lansia tersebut masih merasakan pusingwalaupun sudah melakukan aktifitas dan minum obat. Tujuan mengetahui adanya pengaruh senam lansia terhadap pasien penderita hipertensi pada saat melakukan senam dan setelah melakukan senam lansiadi Puskesmas Pembantu Desa Telaga Tujuh Deli Serdang.

\section{METODE}

Penelitian ini mengunakan metode Preeksperimen desain dengan mengunakan rancangan One Group Pretest-posttest dengan variabel terikat yaitu tekanan darah pada penderita hipertensi dan variabel bebas yaitu senam lansia, melibatkan kelompok subjek dengan diobservasi sebelum dan sesudah dilakukan intervensi (Sugiono, 2018). Pada penelitian ini perlu diobservasi atau dilakukan pengukuran tekanan darah sebelum melakukan senam (pretest) dan setelah dilakukan senam lansia setelah 3 jam dilakukan pemeriksaan (posttest).

Populasi dalam penelitian ini yang digunakan adalah pasien lansia yang menderita hipertensi yang bertempat di Pukesmas Pembantu Telaga Tujuh Kecamatan Labuhan Deli Kabupaten Deli Serdang, adalah berjumlah 60 orang. Sampel dipenelitian ini adalah pengaruh senam lansia terhadap perubahan tekanan darah pada pasien penderita hipertensi di Pukesmas Pembantu Telaga Tujuh Kecamatan Labuhan Deli Kabupaten Deli Serdang berdasarkan sampel untuk penelitian. Teknik pengambilan sampel yang digunakan Non Probability dengan teknik sampel Purposive Sampling. Kriteria Inklusi dari penelitian ini adalah lansia yang bersedia menjadi responden hingga penelitian selesai, lanjut usia dengan umur 50-65t tahun, lanjut usia yang bisa berkomunikasi dengan baik, lansia Yang Tinggal di Desa Telaga Tujuh Deli Serdang, lansia yang bisa aktif bergerak (mobilitas aktif), lansia yang menderita penyakit hipertensi, lansia yang tidak mengkonsumsi obat-obatan farmakologi

Kriteria Eksklusi dari penelitian ini yaitu lansia yang tidak bersedia jadi responden, diatas umur 65 tahun, yang tidak mendengar dan berkomunikasi, yang tidak tinggal di Desa Telaga Tujuh Deli Serdang, lansia yang tidak aktif bergerak, lansia dengan tidak menderita 
penyakit hipertensi, lansia Yang mengkonsumsi obat-obatan farmakologi. Berdasarkan kriteria inklusi yang didapat peneliti menetapkan 20 responden yang menderita penyakit hipertensi. Analisa bevariat adalah untuk mengetahui ratarata pengaruh senam lansia terhadap perubahan tekanan darah pada saat pemberian intervensi dan sebelum pemberian intervensi dengan memakai uji $\mathrm{T}$ - test yaitu untuk melihat perbandingan pada saat sebelum dan sesudah diberikan perlakuan pada variabel dependen, dengan nilai $\mathrm{p}<\alpha$ $(\alpha=0,05)$. Penelitian ini telah lolos etik dari Komisi Rtik Penelitian Kesehatan
Universitas Priima Indonesia dengan Nomor: 011/KEPK/UNPRI/III/2021.

\section{HASIL}

Tabel 1 diketahui bahwa dari 20 responden, mayoritas responden berjenis kelamin perempuan dan minoritas responden laki-laki Usia mayoritas responden adalah 50-55 tahun sedangkan minoritas yakni usia 56-60 tahun. Berdasarkan pendidikan mayoritas tamatan SMA dan minoritas responden adalah yang berpendidikan tamat SD. Berikutnya pekerjaan responden mayoritas buruh tani, dan minoritas responden bekerja sebagai wiraswasta.

Tabel 1.

Karakteristik Responden $(\mathrm{n}=20)$

\begin{tabular}{llcc}
\hline & Karateristik & $\mathrm{f}$ & $\%$ \\
\hline Jenis Kelamin & Perempuan & 18 & 90 \\
& Laki-Laki & 2 & 10 \\
\hline \multirow{2}{*}{ Usia } & 50-55 Tahun & 12 & 60 \\
& 56-60 Tahun & 8 & 40 \\
\hline Pendidikan & SMA & 11 & 55 \\
& SMP & 8 & 40 \\
& SD & 1 & 5 \\
\hline \multirow{3}{*}{ Pekerjaan } & Buruh Tan & 13 & 65 \\
& Ibu Rumah Tangga & 5 & 25 \\
& Wiraswasta & 2 & 10 \\
\hline
\end{tabular}

Tabel 2.

Tekanan Darah Lansia Penderita Hipertensi Sebelum Dilakukan Senam Lansia (n=20)

\begin{tabular}{lcccccccc}
\hline \multirow{2}{*}{ Hipertensi } & \multicolumn{2}{c}{ Hari Pertama } & \multicolumn{2}{c}{ Hari kedua } & \multicolumn{2}{c}{ Hari ketiga } & \multicolumn{2}{c}{ Hari keempat } \\
\cline { 2 - 9 } & $\mathrm{f}$ & $\%$ & $\mathrm{f}$ & $\%$ & $\mathrm{f}$ & $\%$ & $\mathrm{f}$ & $\%$ \\
\hline Sedang & 18 & 90 & 16 & 80 & 12 & 65 & 9 & 45 \\
Ringan & 2 & 10 & 4 & 20 & 5 & 25 & 5 & 25 \\
Terkontrol & - & - & - & - & 2 & 10 & 6 & 30 \\
\hline
\end{tabular}

Tabel 3.

Distribusi Frekuensi Senam Lansia $(n=20)$

\begin{tabular}{lcccccccc}
\hline \multirow{2}{*}{ Senam lansia } & \multicolumn{2}{c}{ Hari Pertama } & \multicolumn{2}{c}{ Hari kedua } & \multicolumn{2}{c}{ Hari ketiga } & \multicolumn{2}{c}{ Hari keempat } \\
\cline { 2 - 9 } & $\mathrm{f}$ & $\%$ & $\mathrm{f}$ & $\%$ & $\mathrm{f}$ & $\%$ & $\mathrm{f}$ & $\%$ \\
\hline Aktif & 20 & 100 & 18 & 90 & 16 & 80 & 13 & 65 \\
Tidak aktif & - & - & 2 & 10 & 4 & 20 & 7 & 35 \\
\hline
\end{tabular}


Tabel 4.

Tekanan Darah Lansia Penderita Hipertensi Setelah Dilakukan Senam Lansia ( $\mathrm{n}=20)$

\begin{tabular}{lcccccccc}
\hline \multirow{2}{*}{ Hipertensi } & \multicolumn{2}{c}{ Hari Pertama } & \multicolumn{2}{c}{ Hari kedua } & \multicolumn{2}{c}{ Hari ketiga } & \multicolumn{2}{c}{ Hari keempat } \\
\cline { 2 - 9 } & $\mathrm{f}$ & $\%$ & $\mathrm{f}$ & $\%$ & $\mathrm{f}$ & $\%$ & $\mathrm{f}$ & $\%$ \\
\hline Sedang & - & - & - & - & - & - & - & - \\
Ringan & 6 & 30 & 4 & 20 & 4 & 20 & 2 & 10 \\
Terkontrol & 14 & 70 & 16 & 80 & 16 & 80 & 18 & 90 \\
\hline
\end{tabular}

Tabel 5.

Tekanan Darah Sistolik dan Diastolik Sebelum dan Sesudah Diberikan Senam Lansia

\begin{tabular}{lccccc}
\hline \multicolumn{1}{c}{ Tekanan Darah } & N & Mean & Median & Sd & Min-Max \\
\hline Sistol pre test & 20 & 140.96 & 140.00 & 11.154 & $120-159$ \\
Sistol post test & 20 & 121.56 & 120.00 & 4.917 & $120-139$ \\
Diastol pre test & 20 & 91.29 & 90.00 & 5.342 & $80-100$ \\
Diastol post test & 20 & 80.76 & 80.00 & 3.342 & $70-89$ \\
\hline
\end{tabular}

Tabel 6.

Hasil Uji Wilcoxon Signed Ranks Test Perubahan Tekanan Darah Sebelum dan Sesudah Dilakukan Senam Lansia pada Lansia Penderita Hipertensi $(n=20)$

\begin{tabular}{cccccc}
\hline \multicolumn{1}{c}{ TD } & $\mathrm{N}$ & Mean & Median & $\mathrm{Z}$ & $\begin{array}{c}\text { P-Value } \\
\text { Pre Test }\end{array}$ \\
\cline { 1 - 3 } Post Test & 20 & 88,70 & 90,00 & $-3,391$ & 0,001 \\
\hline
\end{tabular}

Tabel 2 diketahui bahwa sebelum dilakukan senam lansia (pretest) mayoritas responden memiliki tekanan darah sedang miniroitas tekanan darah ringan. Tabel abel 3 diketahui bahwa responden yang melakukan senam lansia mayoritas aktif dan minoritas tidak aktif.

Tabel 4 diketahui bahwa setelah dilakukan senam lansia (posttest) mayoritas responden memiliki tekanan darah dan minoritas tekanan darah ringan. Tabel 5 menunjukkan bahwa rata-rata tekanan darah sistol sebelum diberikan senam lansia adalah $140 \mathrm{mmHg}$ dan setelah diberikan senam lansia adalah 121 $\mathrm{mmHg}$ sehingga selisih penurunan tekanan darah adalah 20\%. Rata-rata tekanan darah diastolik sebelum diberikan senam lansia adalah $91 \mathrm{mmHg}$ dan setelah diberikan senam lansia adalah 80 mmHg.
Tabel 6 diketahui bahwa skor perubahan tekanan darah hasil uji wilcoxon pada saat di uji pre test hasil nilai mean 88,70 dan nilai median 90,00. Pada saat di uji Post test nilai mean 79,95 dan nilai median 80,00 . Jadi yang didapat hasil nilai $\mathrm{Z}=-3,391$ maka $p$ value sebanyak $0,001<0,05$ sehingga disimpulkan $\mathrm{Ho}$ di tolak dan $\mathrm{Ha}$ terimah. Yang artinya Ada Pengaruh Senam Lansia terhadap Perubahan Tekanan Darah pada Penderita Hipertensi di Puskesmas Telaga Tujuh Deli Serdang 2021.

\section{PEMBAHASAN}

Tekanan Darah Sebelum Diberikan Senam lansia Pada Penderita Hipertensi. Berdasarkan penelitian tentang perubahan tekanan darah pada penderita Hipertensi di dapatkan hasil dengan uji wilcoxon pada saat di uji pre test hasil nilai mean 88,70 dan nilai median 90,00. Pada saat di uji Post test nilai 
mean 79,95 dan nilai median 80,00 . Jadi yang di dapat hasil nilai $\mathrm{Z}=-3,391$ maka $p$ value sebanyak $0,001<0,05$ sehingga disimpulkan Ho di tolak dan Ha terima. Yang artinya Ada Pengaruh Senam Lansia terhadap Perubahan Tekanan Darah pada Penderita Hipertensi di PuskesmasTelagaTujuh Deli Serdang 2021.

Senam lansia merupakan salah satu upaya untuk meningkatkan kesegaran jasmani kelompok lansia yang jumlahnya semakin bertambah, sehingga perlu diberdayakan dan dilaksanakan secara benar, teratur, dan rutin.Senam lansia dapat membantu kekuatan mesin pompa jantung berkurang, dan berbagai pembuluh darah penting khusus di jantung dan otak mengalami kekakuan (Isesreni \& Minropa, 2011).

Senam lansia merupakan rangkaian gerakan yang dirancang khusus bagi lanjut usia. Gerakan-gerakan yang dilakukan pada senam lansia tidak bersifat high impact tetapi low impact yang merpakan rangkaian gerakan kegiatan sehari-hari dengan dipadukan musik yang lembut dan tidak menghentak-hentak yang menimbulkan suasana santai. Gerakan otot yang dipilih adalah gerakan yang tidak terlalu menimbulkan beban dan setiap gerakan dibatasi delapan sampai enam belas kali hitungan sertaiga kali seminggu. Senam lansia dibuat khusus untuk membantu lansia agar dapat mencapai usia lanjut yang sehat, berguna, bahagia, dan sejahtera.

Ada berbagai faktor resiko hipertensi adalah umur, jenis kelamin, riwayat keluarga, genetik, kebiasaan merokok, konsumsi garam, konsumsi lemak, kebiasaan minum-minuman beralkohol, obesitas, kurang aktivitas fisik, stress dan penggunaan estrogen, selain faktor tersebut ada beberapa faktor yang mempengaruhi seseorang tekanan darah hipertensi yaitu masih kurangnya pengetahuan dan sikap mengenai hipertensi (Kementerian Kesehatan Republik Indonesia, 2017).

Tekanan darah setelah dilakukan senam lansia yang terbanyak adalah tekanan darah kategori terkontrol $<120 /<80$ $\mathrm{mmHg}$ yaitu sebanyak 18 orang dan yang sedikit adalah tekanan darah kategori ringan 120-139/80- $89 \mathrm{mmHg}$ yaitu sebanyak 2 orang. Secara mayoritas jika dilihat dari pendapat Zulhaida,dkk (2018) bahwa tekanan darah $<120 /<80 \quad \mathrm{mmHg}$ termasuk kategori normal.

Hipertensi dapat disebabkan karena kurang aktivitas olah raga dan Ari Wulandari (2019)mengatakan orang yang kurang gerak atau kurang olahraga ini memicu kolesterol tinggi dan juga adanya tekanan darah yang terus menguat sehingga memunculkan hipertensi. Oleh sebab itu untuk dapat menurunkan tekanan darah diperlukan olah raga seperti senam.

Salah satu faktor yang bisa mengakibatkan terjadinya tekanan darah mengakibatkan terjadinya tekanan darah meningkat pada lansia yaitu karena faktor kurangnya melakukan aktifitas fisik seperti berolahraga secara teratur (Harrison, Wilson dan Kasper, 2015).Kurangnya latihan aktivitas fisik seperti senam, juga bisa mengakibatkan hipertensi dikarenakan terjadinya penurunan cardiac output (curah jantung) sehingga pemompaan ke jantung menjadi lebih berkurang.Kurangnya latihan aktivitas fisik dapat menyebabkan terjadinya kekakuan pembuluh darah, sehingga aliran darah tersumbat dan dapat menyebabkan hipertensi. Selain itu, 
karena dipengaruhi oleh faktor kurang tidur (insomnia), (Giriwijoyo, 2017)

Hipertensi adalah keadaan peningkatan tekanan darah yang memberi gejala yang akan berlanjut ke suatu organ target seperti stroke (untuk otak), penyakit jantung coroner (pembuluh darah jantung) dan hipertro fiventrikel kanan/left ventricle hypertrophy (otot jantung) (Bustan, 2015). Senam lansia merupakan salah satu upaya untuk meningkatkan kesegaran jasmani, dimana senam lansia ini merupakan serangkaian gerak nada yang teratur dan terarah serta terencana yang dapat di ikuti oleh orang yang lanjut usia dalam bentuk latihan fisik yang berpengaruh terhadap kemampuan fisik lansia. Aktifitas olahraga ini juga dapat membantu tubuh agar tetap sehat dan tetap segar karena juga melatih tulang agar tetap kuat dan dapat membantu menghilangkan radikal bebas yang menyebar dalam tubuh. Senam lansia yaitu suatu bentuk olahraga yang sangat bermanfaat bagi para lanjut usia. Senam lansia yang teratur dapat membantu menjaga keseimbangan tekanan darah sekaligus dapat menurunkan tekanan darah dalam tubuh (Fitria Saftarina \& Fairuz Rabbaniyah, 2016).

Senam lansia ini merupakan salah satu bentuk aktifitas fisik sehingga dapat menurunkan tekanan darah, dimana senam lansia sebagai bentuk olahraga yang dapat mempengaruhi curah jantung serta memperlancar peredaran darah dalam tubuh. Aktivitas fisik seperti senam pada usia lanjut yang dilakukan secara rutin akan meningkatkan kebugaran fisik, sehingga secara tidak langsung senam dapat meningkatkan fungsi jantung dan menurunkan tekanan darah serta mengurangi resiko penumpukan lemak pada dinding pembuluh darah sehingga akan menjaga elastisitasnya. Disisi lain akan melatih otot jantung dalam berkontraksi sehingga kemampuan pemompaannya akan selalu terjaga (Yuli Yantina \& Ajeng Saputri, 2019).

Arif Setiawan (2017) yang mengatakan gerakan dalam senam lansia ini juga mengandung gerakan yang diharapkan dan terbukti bahwa dapat menurunkan tekanan darah pada lansia sekaligus dapat meningkatkan komponen kardiorespirasi, kekuatan dan ketahanan otot, kelenturan dan komposisi badan yang seimbang. Sejalan dengan penelitian yang dilakukan oleh Fitria Saftarina (2017) dengan judul Pengaruh Senam Lansia Terhadap Perubahan Tekanan Darah Pada Penderita Hipertensi Di Wilayah Dusun Kwarasan Nogotirto Sleman Yogyakata, yang menunjukkan bahwa pemberian senam lansia dapat menurunkan tekanan darah sistolik dan diastolik.

Menurut asumsi penelitian bahwa hasil pengukuran tekanan darah setiap sebelum dan sesudah senam didapatkan bahwa dan sesudah senam didapatkan bahwa ada penurunan tekanan darah secara bertahap.Hari pertama responden tidak mengalami perubahan karena mungkin sebagai fase adaptasi. Untuk selanjutnya terdapat penurunan bertahap meskipun olahraga dapat menyebabkan peningkatan tekanan darah selama olahraga, pengulangan aktivitas fisik dapat menurunkan tekanan darah selama istirahat dan peningkatan terhadap olahraga selanjutnya akan lebih baik terhadap penderita hipertensi maupun pada normal. Hipertensi merupakan faktor resiko mayor Penyakit Jantung Koroner (PJK), efek potensial olahraga untuk mengontrol tekanan darah merupakan pertimbangan kesehatan masyarakat yang penting. Senam lansia yang dilakukan berulang- 
ulang (frekuensi tinggi), maka lamakelamaan penurunan tekanan darah akan berlangsung lama. Latihan aktivitas fisik senam yang dilakukan secara teratur bisa menurunkan tekanan darah.Jenis olahraga yang efektif menurunkan tekanan darah.Jenis olahraga yang efektif menurunkan tekanan darah adalah senam lansia dengan intensitas sedang.Frekuensi latihan 3-5 kali seminggu dengan lama latihan 20-60 menit sekali latihan.

\section{SIMPULAN}

Ada pengaruh umur, jenis kelamin, pendidikan, pekerjaan, dan penyakit riwayat Hipertensi pada lansia. Ada pengaruh senam lansia pada perubahan tekanan darah lansia penderita hipertensi. Ada pengaruh senam lansia terhadap penurunan tekanan darah pada pasien penderita hipertensi.

\section{DAFTAR PUSTAKA}

Ari,W.(2019). Cara jitu mengatasi hipertensi.Yogyakarta: Andi

Arif Setiawan. (2017). Senam Lansia Bugar. Purwokerto: IRDH

Anitasari. (2019). Hari Hipertensi Dunia 2019: Know Your Number, Kendalikan Tekanan Darahmu dengan CERDIK. Jurnal. http://p2ptm.kemkes.go.id/kegiata n-p2ptm/pusat-/hari-hipertensidunia-2019-know-your-numberkendalikan-tekanan-darahmudengan-cerdik

Ayu Mutiah,dkk.(2016). Hubungan pengetahuan tentang hipertensi dengan komplikasi pada lansia yang berobat di Puskesmas motoboi kecil kecamatan Kotamobagu Selatan. Jurnal Kedokteran Komunitas dan Tropik https://ejournal.unsrat.ac.id/index.
php/JKKT/article/download/1126 $8 / 10859$

Aisyiah.(2020). Senam lansia menurunkan tekanan darah pada lansia. Journal of Telenursing https://doi.org/https://doi.org/10.3 1539/joting.v1i2.933

Andry Sartika, dkk (2020). Senam Lansia Menurunkan Tekanan Darah Pada Lansia. https://journal.ipm2kpe.or.id/inde x.php/JOTING/article/view/1126

Badan Pusat Statistik.(2019). Statistik Penduduk Lanjut Usia 2019.Jakarta:BPS

Eviyanti, E. (2020). Pengaruh Senam Lansia Terhadap Penurunan Tekanan Darah Di BPSTW Sleman Yogyakarta 2020. Jurnal Kesehatan https://jurnalstikesluwuraya.ac.id/i ndex.php/eq/article/view/32

Ella H. T,.(2019). Pengembangan dan pendampingan senam lansia di masyarakat dungalio kabupaten Gorontalo. Lpm Universitas Negeri Gorontalo. https://repository.ung.ac.id/abdi/s how/1/2126/pengembangan-danpendampingan-senam-lansia-dimasyarakat-dungalio-kabupatengorontalo.html

Eriana, I.(2017). Hubungan Gaya Hidup Dengan Kejadian Hipertensi Pada Pegawai Negeri Sipil UIN Alauddin Makassar Tahun 2017.Skripsi Program Sarjana UIN Alauddin Makassar http://repositori.uinalauddin.ac.id/11505/

F. L. Muh A. Amiruddin, Vennetia R. Dames.(2015).Analisa Hasil Pengukuran Tekanan Darah 
Antara Posisi Duduk Dan Posisi Berdiri Pada Mahasiswa Semester VII (Tujuh) TA. 2014/2015 Fakultas Kedokteran Universitas Sam Ratulangi. J. eBiomedik https://ejournal.unsrat.ac.id/index. php/ebiomedik/article/view/6635

Fitria

Saftarina\&Fairuz Rabbaniyah.(2016). Hubungan Senam Lansia terhadap Kualitas Hidup Lansia yang Menderita Hipertensi di Klinik HC UMMI Kedaton Bandar Lampung. JK Unila.

https://juke.kedokteran.unila.ac.id /index.php/JK/article/view/1637

Herawaty,Dkk.(2015) Senam lansia terhadap penurunan tekanan darah pada lansia dengan hipertensi. Skripsi Fakultas Kedokteran Universitas Lambung Mangkurat. https://ppjp.ulm.ac.id/journal/inde x.php/JDK/article/view/1711

Ifansyah, dkk (2015). Senam lansia terhadap penurunan tekanan darah pada lansia dengan hipertensi. Skripsi Universitas Lambung Mangkurat. https://ppjp.ulm.ac.id/journal/inde x.php/JDK/article/download/1711 $/ 1484$

Kementrian Kesehatan RI.(2018). Profil Kesehatan Indonesia 2017. Jakarta: Kemenkes RI

Kemenkes RI. (2017). Profil Kesehatan Indonesia 2016. Jakarta: Keputusan Menteri kesehatan Republik Indonesia

Kemenkes RI.(2016). Situasi Lanjut Usia (Lansia) di Indonesia. Infodatin Pusat Data dan
Informasi Kementerian Kesehatan Republik Indonesia.

Novita Sari.(2018) Pengaruh pemberian jus semangka (cilitrus vulgaris schrad) terhadap penurunan tekanan darah lansia. Karya Tulis Ilmiah Keperawatan Fakultas Ilmu Kesehatan Universitas Muhammadiyah Purwokerto. http://repository.ump.ac.id/8176/

Noor Diani,dkk 2015). Hubungan Usia, Jenis Kelamin Dan Lama Menderita Diabetes Dengan Kejadian Neuropati Perifer Diabetik. Jurnal Ilmu Kesehatan. https://journal.umbjm.ac.id/index. php/caringnursing/article/download/238/270/

Nanda. (2017). Diagnosis Keperawatan Definisi \& Klasifikasi 2015-2017 Jakarta: EGC

Nursalam. (2011). Konsep dan penerapan metodologi penelitian ilmu keperawatan. Jakarta: Salemba Medika

Notoatmodjo, S. (2017). Metodologi Penelitian Kesehatan. Jakarta : Rineka Cipta

Nuraini, B. (2015). Risk Factors of Hypertension. Faculty of Medicine, University of Lampung. http://juke.kedokteran.unila.ac.id/i ndex.php/majority/article/view/60 2

Rahmi, Upik, dkk. (2016). Gambaran Pengetahuan Lansia Mengenai Senam Lansia Di Panti Sosial Tresna Werdha Budi Pertiwi. Ejorunal upi. https://ejournal.upi.edu/index.php/ JPKI/article/view/2851 
Stanley, M dan Beare, P.G. (2017). Buku Ajar Keperawatan Gerontik. Jakarta:EGC

Saryono \& Widianti. (2017). Catatan Kuliah Kebutuhan Dasar Manusia (KDM). Yogyakarta. Nuha Medika

Saftarina,F. (2016). Pengaruh Senam Lansia Terhadap Perubahan Tekanan Darah Pada Penderita Hipertensi Di Wilayah Dusun Kwarasan Nogotirto Sleman Yogyakata. Jurnal Agromedicine. http://digilib.unisayogya.ac.id/441 8/1/NASKAH\%20PUBLIKASI.p df

Syarifah, S., \& Tarigan, A.R., Lubis, Z. (2018). Pengaruh Pengetahuan, Sikap, Dan Dukungan Keluarga Terhadap Diet Hipertensi Di Desa Hulu Kecamatan Pancur Batu Tahun 2016.Jurnal Kesehatan UIN. http://journal.uinalauddin.ac.id/index.php/kesehata n/article/view/5107

Susanti, N. (2020). Determinan Kejadian Hipertensi Masyarakat Pesisir Berdasarkan Kondisi Sosio Demografi dan Konsumsi Makan. Jurnal Ilmiah Kesehatan. https://www.neliti.com/publicatio ns/325868/determinan-kejadianhipertensi masyarakat-pesisirberdasarkan-kondisi-sosio-demo

Sugiyono. (2018). Metode Penelitian Kuantitatif. Bandung: Alfabeta.

Triyanto E.(2018). Pelayanan Keperawatan Bagi Penderita Hipertensi Secara Terpadu. Yogyakarta: Graha Ilmu

Trisnanto. (2016). Pengaruh Senam Lansia Terhadap Penurunan Tekanan Darah Pada Lansia dengan Hipertensi grade I-II di Posyandu lansia RT 05 RW 03 Kelurahan Bogo Kecamatan Nganjuk Kabupaten Nganjuk. https://ojs.unpkediri.ac.id/index.p hp/akper/article/view/413

Vedyawati Rita.(2018). Pengaruh Senam Anti Hipertensi Lansia Terhadap Penurunan Tekanan Darah Lansia Di Desa Kemuningsari Lor Kecamatan Panti Kabupaten Jember. The Indonesian Journal Of Health Science.

http://repository.unej.ac.id/xmlui/ handle/123456789/89801

Wahyu,R.U.(2015). Mengenal dan Mencegah Penyakit Diabetes, Hipertensi, Jantung dan Stroke Untuk Hidup Lebih Berkualitas. Yogyakarta: Media Ilmu

Yonata,A \& Pratama,A.S.P.(2016). Hipertensi sebagai Faktor Pencetus Terjadinya Stroke.Jurnal Majority.

https://juke.kedokteran.unila.ac.id /index.php/majority/article/view/1 030

Yuli Yantina\& Ajeng Saputri. (2019). Pengaruh senam lansia terhadap tekanan darah pada wanita lansia dengan hipertensi di wilayah kerja puskesmas banjarsari metro utara tahun 2018. Jurnal Farmasi Malahayati.

http://ejurnalmalahayati.ac.id/inde x.php/farmasi/article/view/1549

Zulhaida,dkk. (2018). Pengaruh Pengetahuan, Sikap, Dan Dukungan Keluarga Terhadap Diet Hipertensi Di Desa Hulu Kecamatan Pancur Batu Tahun 2018.Jurnal Kesehatan UIN. http://journal.uin- 
Jurnal Penelitian Perawat Profesional, Volume 3 No 2 Hal 347 - 358, Mei 2021

Global Health Science Group

alauddin.ac.id/index.php/kesehata n/article/view/5107 